The University of Akron

\title{
IdeaExchange@UAkron
}

Proceedings from the Document Academy

University of Akron Press Managed

December 2017

\section{The Materiality of Documents and the Genocidal Continuum}

\author{
Martin I. Nord \\ University of Western Ontario, mnord@uwo.ca \\ D. Grant Campbell \\ University of Western Ontario, gcampbel@uwo.ca
}

Please take a moment to share how this work helps you through this survey. Your feedback will be important as we plan further development of our repository.

Follow this and additional works at: https://ideaexchange.uakron.edu/docam

Part of the Library and Information Science Commons

\section{Recommended Citation}

Nord, Martin I. and Campbell, D. Grant (2017) "The Materiality of Documents and the Genocidal Continuum," Proceedings from the Document Academy: Vol. 4 : Iss. 2 , Article 2.

DOI: https://doi.org/10.35492/docam/4/2/2

Available at: https://ideaexchange.uakron.edu/docam/vol4/iss2/2

This Conference Proceeding is brought to you for free and open access by University of Akron Press Managed at IdeaExchange@UAkron, the institutional repository of The University of Akron in Akron, Ohio, USA. It has been accepted for inclusion in Proceedings from the Document Academy by an authorized administrator of

IdeaExchange@UAkron.For more information, please contact mjon@uakron.edu, uapress@uakron.edu. 
In a recent symposium on the Ethics of Apology, held at the University of Toronto, scholar Mayana Slobodian recounted the experience of attending one of the national events held by the Canadian Truth and Reconciliation Commission (TRC), investigating the mistreatment of Indigenous children in Canada's Residential School system throughout the $20^{\text {th }}$ century. In her account, she noted the comparative absence of the Canadian Federal Government from the event in Ottawa, as well as the presence of copies of the Federal Government's Official Apology of 2008:

Adjacent to the main hall there was a large foyer filled with craft vendors, advocacy organizations and churches, selling crafts and things like this, and that's where the Federal Government was. ... There was a large sign reading Government of Canada hanging above a table that was covered in Canadian flag pins and stickers; there were photos of the stained glass window in Parliament that was created to commemorate the Residential Schools; and also, in a kind of big pile-I still can't believe this - passersby were invited to take a printed copy of the Canadian apology, the official apology, and it was printed out on a piece of paper with kind of faux aged edges, and kind of old-timey font. I don't know if they were going for a treaty, but it was rolled up like a scroll. And that was the inauspicious end of the official apology at the TRC (2017).

Slobodian's emphasis on the unfortunate optics surrounding an important document in Canada's history of its relationship with Indigenous peoples emphasizes the degree to which this relationship is saturated with material documents. The appearance of the copies of the Apology-manufactured to look antique and picturesque, piled high at an unattended table among craft vendorsactively worked against the semantic content of the document itself, placing its words within a performance of perfunctory, condescending, and indifferent response. Documents have historically played, and continue to play, an important symbolic role in Canada's recognition and acknowledgment of the injustices committed in the residential schools: the Statement of Reconciliation in 1998, the official Apology of 2008, and the Report of the Truth and Reconciliation Commission in 2015, and the numerous documents that have emerged in response to the TRC's calls to action. In this paper, we argue that the role of documents in this process is intimately related to the discourse of cultural genocide. Furthermore, we argue that material documents play a fundamental role in the process of a nation's evolving response to the evidence of cultural genocide. Somewhat paradoxically, they are crucial to the creation of what Gadamer (2006) calls a "fusion of horizons:" (305) the slow and painful process of breaking down the barriers between Self and Other. 
Documents play a complex role in cases of cultural genocide: a role that merits considerable attention. The history of Indigenous cultures and communities in Canada since before Confederation in 1867 is dotted with documents: the Indian Act in all its various manifestations and revisions; the White Paper of 1969, which advocated the end of Indian status and the assimilation of Indigenous peoples into mainstream Canadian society; and more recently the Report of the Truth and Reconciliation Commission, which exposed the activities of the Residential School system, established by the Canadian Federal Government, and administrated by the Catholic, Anglican, Presbyterian, United, and Methodist Churches (TRC, 2015, 3). As Canada as a society slowly comes to acknowledge the Residential Schools as the central element in a case of cultural genocide, even more documents are appearing: various apologies and gestures of reconciliation, including the Federal Government's formal apology in 2008; formal apologies by various churches, such as the United Church's apology in 1998; and archival undertakings such as the Project Naming initiative at Library and Archives Canada (LAC), which enables Inuit elders and their communities to identify figures in LAC's archive of photographs in the North in 2009. Above all, governments, churches, academic institutions, and libraries are documenting their determination to respond to the Truth and Reconciliation Committee's 94 Calls to Action. The Report of the Truth and Reconciliation demands that these mainstream, normative bodies take concrete steps to acknowledge the residential schools as cultural genocide, to promote the healing process, and to repair the damage as far as possible.

Within the Canadian library community, the Canadian Federation of Library Associations (CFLA, 2017) instituted its own Truth \& Reconciliation Committee, which, in February 2017, produced a report that included a set of recommendations for libraries to respond to the TRC's Calls to Action. Utilizing the medicine wheel framework, as the paradigm most congenial to the Indigenous world view, the Committee classified the recommended responses of the library community into four sectors representing Winter (North), Spring (East), Summer (South) and Fall (West). The Spring, or East, sector looked to the Future, and advocated an ambitious program of decolonizing libraries and space, access and classification, together with programs for the protection of Indigenous knowledge (CFLA, 2017, 4). These recommendations included:

- Addressing structural biases in existing schemes of knowledge organization and information retrieval, integrating Indigenous epistemologies into cataloguing praxis and knowledge management;

- Implementing Indigenous Knowledge Protection protocols and agreements, to protect Indigenous materials held in libraries, archives and cultural memory institutions. (CFLA, 2017, 5) 
In addition, the CFLA advocates the creation of a database of "living documents," designed to establish and disseminate Best Practices for Indigenous services in libraries and other information institutions (CFLA, 2017, 6).

For the library community to respond meaningfully to the Truth and Reconciliation Commission's Calls to Action, it must confront two challenges. First, it must recognize that the Commission has decisively and explicitly defined the Canadian Residential Schools as an act of cultural genocide: "the destruction of those structures and practices that allow the group to continue as a group. States that engage in cultural genocide set out to destroy the political and social institutions of the targeted group" (TRC, 2015, 1). Acceptance of the TRC's Calls to Action, therefore, casts the library community's responses as responses to cultural genocide. Second, the library community must acknowledge and facilitate the crucial relationship between material documents and cultural genocide. In particular, it must examine and facilitate the role that material documents play in a society's arduous and long-term efforts to acknowledge cultural genocide and to repair the damage caused by such genocide. To that end, library systems of documentation, organization, classification, and dissemination must be examined through the lens of genocide studies, and the light that such studies throw upon the creation, classification, and use of documents.

Genocide studies' investigation of the causes of genocide increasingly rejects the fallacy that genocide is an extraordinary thing that is unlikely to happen here or now or among people like us. Instead, it points to the roots of genocide in everyday things. When prompted to consider genocide, our thoughts may first turn towards events perpetrated under totalitarian regimes. Barbara Harff reminds us, however, that genocides have occurred at the direction of democratic institutions and with the indirect and direct aid of ordinary individuals (1987, 41-42). Following a similar line of thinking, Ervin Staub points out the many ways in which we are bystanders - to victims of discrimination, to the homeless, to victims of violence in other countries, or to our own governments' violent policies - and how this may lend itself to an "ongoing, usually progressive increasing mistreatment of a group of people" $(2003,292)$. Clearly, we need to investigate something more common to humanity than individual dictators such as Hitler if we want to better understand genocide. The most basic of human endeavors - in which documents occupy a key position - is our communication with others. If the roots of genocide are hidden in everyday things, documents must be interrogated.

Nancy Scheper-Hughes' concept of the genocidal continuum helps us to do this. She defines the genocidal continuum as "comprised of a multitude of 'small wars and invisible genocides' conducted in the normative spaces of public schools, clinics, emergency rooms, hospital wards, nursing homes, court rooms, prisons, detention centers, and public morgues" $(2003,178)$. Inherent to these social violences is the objectification of "the Other." Scheper-Hughes continues her 
definition with the realization that the continuum "refers to the capacity to reduce other humans to nonpersons, monsters, or things, which gives license to institutionalized forms of mass violence" $(2003,178)$. By positioning these reductions along a continuum, Scheper-Hughes enables us to see a society's everyday actions as a series of seemingly infinitesimal movements, towards a state of genocide or away from it.

We acknowledge the abstracting quality of Scheper-Hughes' concept, agreeing with her that we must weigh the "moral risk of overextending the concept of 'genocide' into spaces and corners of everyday life where we might not ordinarily think to find it" with the danger that lies in "failing to sensitize ourselves, in misrecognizing, [sic] protogenocidal sentiments that are enacted every day and in peacetime" (179). We believe the latter risk is not only greater, but also points us toward the utility of the continuum as a conceptual tool. We use it to refocus our questions and point us to a location of inquiry in the form or normative spaces and to a process to interrogate in the form of objectification of the Other.

A continuum does not automatically imply movement. Just because things exist at points along continuums does not then mean that they necessarily move towards the poles of that continuum. However, Scheper-Hughes posits the genocidal continuum as something explored either as a genealogy of genocide or as a first step toward "undoing' evil and remaking a shattered world" (168). She also notes that genocide is "normally socially, [and] politically incremental" (192). These ideas connect the continuum to change over time, and therefore movement. When thinking about genocide, we may be prone to focus on the movement toward genocide first and foremost, concerned especially with causes and fault. However, movement exists in retreat from genocide as well, in processes usually labelled as reconciliation. Individual and social responses to documents may operate in both directions, sometimes simultaneously.

Scheper-Hughes does not provide an exact definition of normative spaces, but we can approximate one from how she describes her decades of anthropological work on family farms of West Kerry, Ireland and in shantytown favelas of Northeast Brazil, and then finally through her own parents' experience in "Happy Valley" Nursing Care Center near Baltimore. What binds these places together is their relative ordinariness. Within their respective societies, they are not unusual places. We find another clue in Scheper-Hughes' understanding of the origins of violence, which she locates in humanity's social nature as "cultures, social structures, ideas, and ideologies shape all dimensions of violence, both its expressions and its repressions" (3) In other words, individuals can be violent, but violence is especially shaped by social institutions: normative spaces that we often look to for guidance or assistance. This recognition changes how we look at violence, which is often not deviant, but may be applauded as "virtuous action in the service ... of norms" (171). We are left in an uncomfortable position, perhaps 
looking over our shoulders to see if violence is hiding in the institutions that are so familiar to us. Documents are interwoven in such normative spaces. Frohmann (2004) reminds us that "materiality is a function of institutionalized routines of significant repetition" (151). Violence may be hiding in our documents too.

According to the Truth and Reconciliation Commission, Canada's Residential Schools served to destroy the structures and practices, and the political and social institutions of Indigenous peoples in Canada. Adopting ScheperHughes's paradigm of a continuum defined within normative spaces, we can see this cultural genocide as the product of violence that was both shaped and permitted by Canadian social institutions, including both the federal government and various Christian church denominations. If, as Frohmann suggests, material documents entrench institutionalized routines through repetition, then documents had a role in instantiating the acts of violence that constitute cultural genocide.

We wish to suggest, in the remainder of this paper, that if documents facilitate cultural genocide, documents also provide a means to recover and repair the damage. Using the theories of Hans-Georg Gadamer, we examine how documentary practice, particularly in response to the TRC's Calls to Action, has the potential to move Canadian society along the genocidal continuum away from those conditions that enabled cultural genocide. This potential is evident in the CFLA's Report and Recommendations. The role that documents play, we argue, is intimately related to changes in our ways of knowing others, as explored in the philosophical hermeneutics of Hans-Georg Gadamer.

Like Scheper-Hughes, Gadamer (2006) addresses our capacity to reduce others to something that is not human. His philosophical hermeneutics provides one of the solutions that moves us along the continuum away from the pole of genocide toward reconciliation. Gadamer references knowing the Other most explicitly in his exploration of I and Thou (the self and the fellow human being). He compares threes kinds of experience of the Thou and how they relate to the hermeneutic experience. In the first kind of experience, I experience Thou as a subject of inquiry. In the second kind, I acknowledge that Thou is a person, but still understand Thou as a form of self-relatedness in which Thou is only understood from the standpoint of I.

The third kind of experience is one where relations to Thou are characterized by openness. This is the only way a genuine relationship can exist, one in which we "experience the Thou truly as a Thou-i.e., not to overlook his claim but to let him really say something to us" (Gadamer, 355). Openness operates in both directions, both for Thou who speaks and for I who listens: "Belonging together always also means being able to listen to one another" (355). In this open dialogue, I must accept without coercion, "some things that are against me" (355). This third experience in the hermeneutic sphere is essentially the fusion of horizons - the term that summarizes Gadamer's project. As one's vantage point 
changes, one's horizon also changes; it is not fixed. As the horizon moves, it fuses with other horizons, those of the Other. Understanding occurs when I and Thou engage in dialogue with each other. This does not happen without tension. Thou poses a question to I, which "breaks open" the thing to be revealed and leads us to question what Gadamer calls our historically effected consciousness. This does not happen as an abstract change to our knowledge but instead as something more qualitative, perhaps surprise or confusion, things we are not in control of. When we encounter the Other in openness, we are forced to recognize what we do not know about that Other. We may not learn much more about them, but we can no longer regard them as an object of inquiry. Openness is the key to this essential encounter, and it is the openness offered by documents that we want to interrogate.

To what extent can documents allow Thou to really say something to I and to what extent do documents allow Thou to question I? This becomes an especially significant question in the contemporary context of the so-called information society, with its conflicting claims about the affordances of a highly-connected world. We can claim that there is something beneficial to the face-to-face encounter that is too often lacking in this context without despairing of any useful role for documents as a thing between individuals. This "betweenness" exists in the faceto-face encounter too, and even in our own attempts to understand ourselves. We will never achieve full understanding of selves, and the presence or absence of documents will not change that. But documents do perform a role between selves, and that role is our concern.

Documents are used to communicate and thus operate at a collective level. We know from Suzanne Briet that documents are things that are "brought into public knowledge" $(2006,10)$. Frohmann adds to our understanding of this public role through his emphasis on the institutional practices that surround documents. Each highlights the relationship between documents at the collective level. Our consideration of ethics leads us to include individuals in this relationship. In addition to the association between documents, we should look at the relationship between individuals as connected through the document. Documents function then as "collective moral passages," in the words of Bowker and Star $(1999,6)$, where the long term, collective choices society makes have ethical implications.

Ideally, ethics are lived. Gadamer (2006), drawing on Aristotle, describes phronesis or practical, lived wisdom. We cannot plan for situations we may encounter that demand moral action because they are always new. There is no time for reflection: instead we either act or refrain from acting. However, ethical practices become institutionally embedded in documents in the form of norms and deontologies, or ethical guidelines, such as the Universal Declaration of Human Rights. These are not the ideal of lived wisdom, but rather the materialization of ethical meaning as an object. Not all deontologies are materialized as documents, 
but those that are tend to guide and constrain society and institutions at the highest level.

We know from Gadamer that ethics as phronesis does not have a specific form. Once we embed ethics in a document, however, it has an exact form that is determined by the constraints of the document. If the concept of ethics has not been transcribed into the document, it effectively does not exist at the institutional and social level, despite what the individual may think. The mere fact that these ideals are documented, the fact that they exist as something concrete in the world, means that society has to deal with them. Individual beliefs run up against the documented beliefs, against which they are measured, and if they are not found to be in agreement, the individual must work to amend the document or write a competing document. This is not to say that social groups cannot collectively hold a belief that competes with those embedded in a document, but they must always contend with the document. Thus, the document functions as an anchor that keeps social norms in relative place, but allows small movements, much as an anchor keeps the ship in place but allows movement with the tide. The norms inscribed in the document appear to have a great deal of power, yet they are not active. They cannot force individuals to live their ideals. The material document acts as a solid reference point for action, but cannot take action itself.

By way of analogy, we may describe documents, and by extension the concepts that they contain, as stones over which we stumble as we make our way. They impact us, whatever we may do after we trip. They force an encounter, which may then lead to understanding and phronesis in the Gadamerian sense. The action may be ours, but it is in response to these objects set in our path.

The TRC Report (2015) functions in exactly this way. The report comes out of a long process of dialogue with other documents and, more importantly, with individuals, especially those impacted by the Indian Residential Schools and their legacy. The complexities of that dialogue cannot be contained in the document, where they have been turned into a text constrained by the material rules of recording, writing, and publishing. We may look at the Report and see the Other reduced. It is right to recognize this, the ways in which the Report might threaten to render the Indigenous individuals as subjects of inquiry. If many individuals experience the reduced meaning of the Other in this way-not living according to the ideals offered by the Report - the cumulative effect would be to maintain Canada's current point on the genocidal continuum or even move it closer to the genocidal pole. With either of these possible outcomes, cultural genocide remains a worry.

However, we must also acknowledge the good that may come from this report. The report consistently articulates goals that reflect Gadamerian understanding: truth discovered through relationship, through encounters, and through reconsideration. To the extent that this meaning is now socially entrenched 
because it materially exists in the Report, it places the Other in front of us where we must consider him or her at the personal level, whether or not our response to that experience is ethical. At the social level, the report anchors current norms. Changes to social deontology concerning Indigenous people will now have to engage in dialogue with this document. There is no way around this. In this way, it is likely that the report is moving Canada away from the genocidal pole of the continuum, at least at the level of collective moral passage. If nothing else, the Report as an institutional tool calls for other institutional documents in the form of formal statements of response from such normative spaces as the government and churches. Actual understanding may depend on individual interaction with the document, but the document will always function as a reference point for phronesis in that interaction. The Settler-Colonial "I" interacting with the Indigenous "Thou" may act ethically based on a fusion of horizons with the Report.

Documents, therefore, play a significant role in the "fusion of horizons" that will hopefully occur as mainstream Canadians and their institutions respond to the TRC's Calls to Action, including calls to de-colonize information environments such as libraries. And insights and findings from the field of transitional justice suggest that this de-colonization will follow a pattern of slow movement, characterized by uneasy stages in which documents will play a key role.

In comparing the work of the TRC to other reconciliation commissions in other countries, Matt James argues that the truth commission faces significant challenges, and that Canada resembles, to some degree, countries that have had the least success in reconciliation: "Canada shares some similarities with those truth commission countries whose political contexts have been least hospitable to thoroughgoing processes of accountability and truth" (2017). One problem lies with the prevailing discourse of "healing" in the conduct of the TRC, which has led the commission to focus on the testimony of residential school survivors with an emphasis on the therapeutic effects of telling one's story, while ignoring issues of colonial governance that created the problem in the first place, and which have by no means been dislodged (James, 2012; Storrie, 2015, 476). In particular, this emphasis on healing prevents the inclusion of perpetrators' voices, and prevents "an interplay between victim and perpetrator" (Storrie, 2015, 477), that would lead to the fusion of horizons that Gadamer advocates.

In a recent presentation at the same symposium on the Ethics of Apology (2017) that featured Mayana Slobodian, however, Matt James and Jordan StangerRoss have analyzed the process of government apologies in a way that lends credence both to the importance of documents, and to seeing documents along a genocidal continuum. They argue convincingly that the realities of transitional justice prevent us from seeing formal, documented apologies as things that only happen once. Rather, they happen through an iterative process, in which each document, in addition to expressing a collective societal gesture of recognition of 
an injustice, also marks a distinct stage of acknowledgement. The first Canadian federal government apology for the residential schools, the Liberal Government's Statement of Reconciliation in 1998, acknowledged that injustices had occurred within the residential schools. The Conservative Government's Apology in 2008 acknowledged that the residential schools, far from being mere sites of injustices, were an injustice in themselves, products of racial prejudice that Canada no longer deemed acceptable. The findings of the Truth and Reconciliation Commission, however, have forced a further recognition: that the schools in themselves were "instruments of land and sovereignty dispossession" (James \& Stanger-Ross 2017). These documents represent stages in a collective act of the fusion of horizons, as Canadians, both as individuals and as institutions and collective bodies of thought and action, struggle to recognize the violence in its familiar normative spaces.

Documents, therefore, will continue to occupy a crucial role in Canada's long and arduous process towards acknowledging the cultural genocide that took place in the $20^{\text {th }}$ century, and repairing the damage that was done. If, as the Canadian Federation of Library Associations intends, Canadian libraries will work to de-colonize library spaces and create databases of living documents, they must organize, describe and provide access to these documents in a way that does justice to a slow and halting movement along a continuum, away from the conditions of cultural genocide, towards an ever-receding, constantly uncomfortable, but ultimately rewarding fusion of horizons.

\section{REFERENCES}

Bowker, G. C. and Star, S. L. (1999). Sorting things out: Classification and its consequences. Cambridge, MA: The MIT Press.

Briet, S. (2006). What is documentation? English translation of the classic French text (R. E. Day, L. Martinet, \& H. G. B. Anghelescu, Ed. \& Trans.). Lanham, MD: The Scarecrow Press.

Canadian Federation of Library Associations (2017). Truth \& Reconciliation Committee report \& recommendations. Retrieved from http://cflafcab.ca/en/indigenous/trc_report/

Frohmann, B. (2004). Deflating information: From science studies to documentation. Toronto: University of Toronto Press.

Gadamer, H.-G. (2006). Truth and knowledge. (3rd rev. ed.). (J. Weinsheimer, Trans.). New York: Continuum. (Original work published 1960)

Harff, B. (2000). The etiology of genocides. In I. Walliman \& M. Dobkowski (Eds.), Genocide and the modern age: Etiology and case studies of mass death (pp. 41-59). Syracuse: Syracuse University Press.

James, M. (2012). A carnival of truth? Knowledge, ignorance and the Canadian Truth and Reconciliation Commission. International journal of transitional justice, 6, 182-204. 
James, M. (2010). Uncomfortable comparisons: The Canadian Truth and Reconciliation Committee in international context. Les ateliers de l'éthique / Ethics forum, 5(2).

James, M., \& Stanger-Ross, J. (2017). Impermanent apologies: On the dynamics of timing and public knowledge in political apology. The ethics of apology: Interdisciplinary and international perspectives. Toronto: Centre for Ethics, University of Toronto. Retrieved from https://www.youtube.com/watch?v=r0Z0loYiCgk\&t=586s.

Scheper-Hughes, N. (2003). A genealogy of genocide. Modern Psychoanalysis, 28(2), 167-197.

Scheper-Hughes, N., \& Bourgois, P. (Eds.). (2004). Violence in war and peace. Malden, MA: Blackwell Publishers.

Slobodian, M. (2017). Finding Canada's Official Apology at the Truth and Reconciliation Commission. The ethics of apology: Interdisciplinary and international perspectives. Toronto: Centre for Ethics, University of Toronto. Retrieved from https://www.youtube.com/watch?v=Uw03hfIOE3Y

Staub, E. (2003). The psychology of bystanders, perpetrators, and heroic helpers. In The psychology of good and evil: Why children, adults, and groups help and harm others (pp. 291-324). New York: Cambridge University Press.

Storrie, B. (2015). 'The mighty life-creating and transforming power' of carnival: Why the Truth and Reconciliation Commission does not seem to have it, but Indigenous resurgence does. International journal of transitional justice, 9, 469485.

Truth and Reconciliation Commission of Canada. (2015). Honouring the truth, reconciling for the future: Summary of the Final Report of the Truth and Reconciliation Commission of Canada. Ottawa: The Commission. 